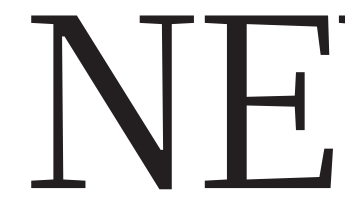

CLIMATE CHANGE Himalayan nations brace for coming floods and droughts p.14
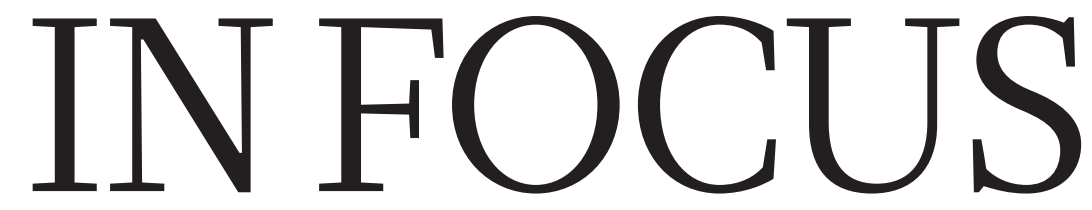

ASTRONOMY NASA won't let Kepler go gentle into that good night p.16
COGNITION A 'brain training' computer game that works p.18
MARINE SCIENCE The biologist

who ran off to sea to

'study it all' p.20

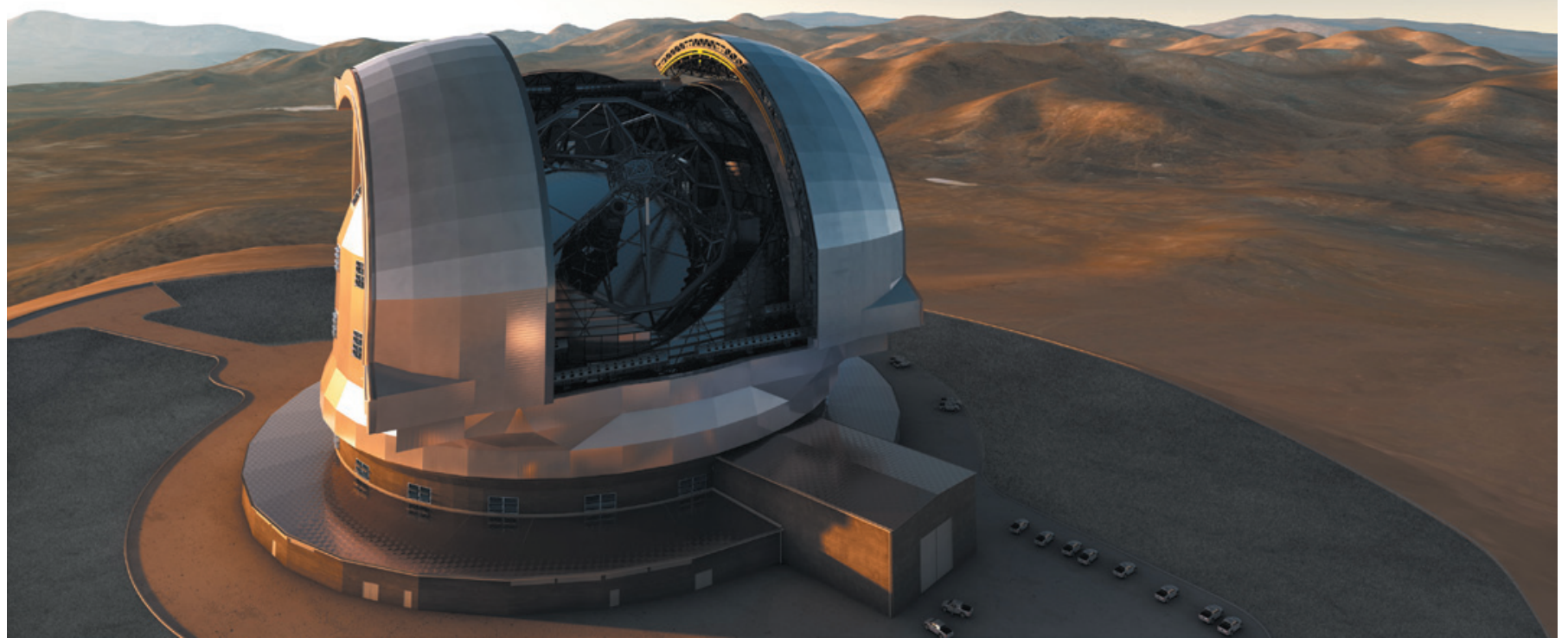

The 39-metre Extremely Large Telescope in Chile (artist's impression) will suffer setbacks without Brazilian money.

\title{
ASTRONOMY
}

\section{Brazil delays stargazing pact}

\section{Reluctance to pay entrance fees stalls European Southern Observatory's giant telescope.}

\section{BY RAFAEL GARCIA}

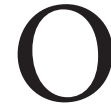
n 28 August, Jorge Meléndez stepped into a room full of journalists to announce a remarkable discovery: an 8.2-billion-year-old star that was depleted in elements such as iron and aluminium in almost exactly the same way as the Sun - a hint that the older star could host terrestrial planets. In an age when astronomers are obsessed with finding another Earth, Meléndez had found something nearly as exciting: a solar twin.

Even more significant than the discovery were its circumstances. Meléndez, an astronomer at the University of São Paulo, Brazil, had found the star using an elite telescope that belongs to the European Southern Observatory (ESO) - a sign of a functioning, if fragile, transatlantic co-dependency.

In 2010, Brazil signed an agreement with ESO, becoming the organization's first
non-European member. Brazil's membership fees would allow ESO to begin construction of its €1.1-billion (US\$1.5-billion), 39-metre Extremely Large Telescope (ELT). In return, Brazil's small but growing cadre of astronomers would get access to ESO's existing telescopes in Chile. Meléndez's discovery came after just two nights of observation at the Very Large Telescope, ESO's premier observatory, in the Atacama Desert. He has been granted a further 88 nights at ESO's La Silla Observatory, where he is looking for planets that orbit solar twins. "Before the ESO agreement, it would have been impossible for me to do this," he says.

But the relationship has started to fray. Nearly three years after the agreement was signed, Brazil's Congress still has not ratified it. The country has made nominal membership payments of $€ 4$ million a year, maintaining access to ESO telescopes for astronomers such as Meléndez, but has not coughed up its full entrance fees and annual dues, which are expected to total about $€ 270$ million over a decade. ESO officials say that further delays will cause the nation to miss out on lucrative construction contracts for the ELT, which will be solicited by the end of this year. "The longer Brazil waits, the more it risks compromising the opportunity for Brazilian companies to be awarded such large contracts," says Tim de Zeeuw, director-general of ESO at its headquarters in Garching, Germany.

No one in Brazil's executive government is pushing the agreement. The science minister who signed it, Sergio Rezende, left the cabinet just days later, and his successor did nothing with the document. It was not until this February, more than a year after the arrival of current minister Marco Antonio Raupp, that the agreement was formally sent to Congress for ratification. But Raupp, whose emphasis has been on innovation and applied science 
- over basic research since his term began, is not seen as a champion of ESO membership.

That has essentially left Brazilian astronomers to lobby Congress on their own. And not all of them are in favour of joining ESO; some see it as an expensive step that will bankrupt more modest, home-grown efforts to nurture Brazilian astronomy.

João Steiner, an astronomer at the University of São Paulo, is the most vocal critic of ESO membership. He argues that Brazil's fees - which are based on the country's gross domestic product - are comparable to those of Italy and the United Kingdom, even though Brazil has fewer astronomers, and fewer still with research programmes mature enough to compete for observation time. "It doesn't make sense for us to subsidize European science with Brazilian taxpayers' money," says Steiner.

He would prefer Brazilian astronomers to work with more affordable telescopes. These include Gemini, two 8-metre telescopes in Chile and Hawaii, run by six countries including Brazil; the Southern Astrophysical Research Telescope (SOAR), a 4.1-metre instrument in Chile part-owned by Brazil; and a 1.6-metre telescope at Brazil's own Pico dos Dias Observatory near Itajubá.

But Marcio Maia, an astronomer at the National Observatory in Rio de Janeiro, says that his country should be ambitious. "If Brazil wants to remain in the Stone Age of astronomy, we can do it at the city of Itajubá, where there is nothing to be seen, we can keep our meagre share at Gemini or we can use SOAR, a telescope with no good instrument," he says. "We can only learn how to do cutting-edge astronomy by entering the competition and fighting for it."

Steiner acknowledges that joining ESO would bring benefits, but says that the fees are too high at a time when Brazil is unlikely to take on expensive projects. In July, the government announced a 10-billion-real (US\$4.3-billion) cut to overall federal expenses. And the Ministry of Science, Technology and Innovation has little room in its own budget; it says that it would have to commit $12 \%$ of its general funding to honour the ESO agreement if Congress does not approve new spending for it. Such a commitment is unlikely from Raupp, who has blamed the delay in ratification on the lack of consensus. "The strong divide in the Brazilian astronomical community is certainly an important fact that cannot be ignored," says José Roberto Ferreira, a spokesman for Raupp.

But contrarians such as Steiner seem to be in the minority, according to a 2010 poll by the Brazilian Astronomical Society. In interviews of 180 of the society's 660 astronomers, $75 \%$ supported the ESO agreement. Another 17\% (mostly theoretical cosmologists) declined to vote; just $8 \%$ were against membership.

Even with strong support from astronomers, however, it will be difficult to persuade Congress to approve membership by the end of 2013.

If Brazil fails to ratify the agreement, ESO could boost its funding by adding other member states. Russia, Poland, Canada and Australia have all expressed interest. "We are being regularly approached by other countries," says de Zeeuw. But it would be years before money from any new member would arrive. If ESO wants to build the ELT, it has few choices but to wait for Brazil.

\section{Floods spur mountain study}

\section{Himalayan nations take action in response to changing climate and its deadly effects.}

\section{BY JANE QIU}

A snapshot of weather-related disasters in the Himalayas suggests that things are amiss on the roof of the world.

This spring, for example, western Nepal was hit by a severe drought, leading to crop failures and exacerbating an already serious food crisis. In June, the same region was devastated by its worst floods in 50 years, caused by unusually intense monsoon rains. The deluge wreaked havoc in the northern Indian states of Uttarakhand and Himachal Pradesh, killing at least 5,700 people and causing an estimated loss of US $\$ 2$ billion.

After decades of such climate-related incidents, the eight member countries of the International Centre for Integrated Mountain Development (ICIMOD), a regional body, have agreed that enough is enough. On Monday, they launched a three-year study that aims to comprehensively assess the current state of the Hindu Kush Himalayas, the enormous area sustained by the world's highest mountain range, and to make recommendations on how it might be safeguarded and developed.

And none too soon, say many scientists. As climate change tightens its grip, "disasters will become increasingly frequent", says

\section{TROUBLE IN STORE}

Across the Himalayas (main river basins shown), average temperatures and rainfall are rising by $0.6^{\circ} \mathrm{C}$ and 65 millimetres a decade, respectively, leading to increased glacier melt and flooding, and prolonged droughts.
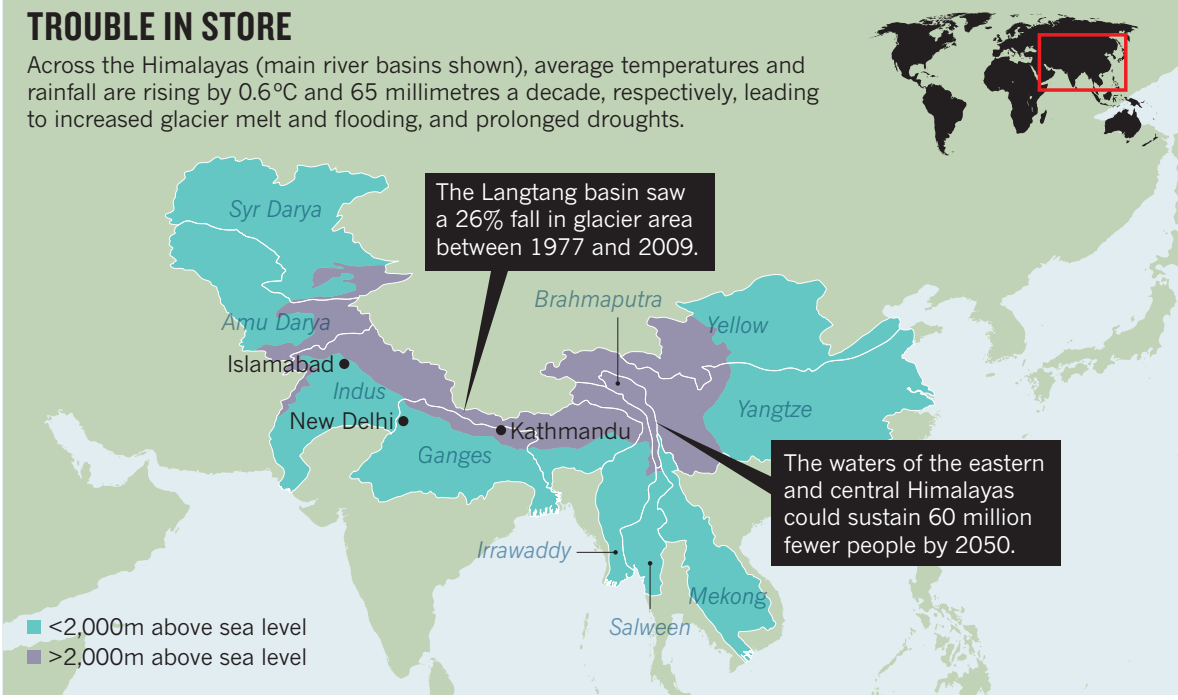

Vinod Tewari, a geologist at the Wadia Institute of Himalayan Geology in Dehradun, India. The Himalayas are getting warmer at a rate of $0.6^{\circ} \mathrm{C}$ each decade, three times the global average ${ }^{1}$. Rainfall there is increasing at a rate of 65 millimetres per decade and the monsoon season is getting wetter ${ }^{1}$. However, winters are getting drier (see 'Trouble in store').

As a result of the warming, most Himalayan glaciers are retreating rapidly. Glacier lakes are becoming larger and more numerous, inundating pastures and threatening downstream communities. The changing climate is also "taking a toll on alpine pastures and forests", says Maharaj Pandit, an ecologist at the University of Delhi in New Delhi. Some plants are shifting to higher altitudes ${ }^{2}$, others are on the verge of extinction, and the incidence of invasive 